\title{
Dialysis Catheter Infection
}

National Cancer Institute

\section{Source}

National Cancer Institute. Dialysis Catheter Infection. NCI Thesaurus. Code C114723.

A local or systemic infection associated with the use of a dialysis catheter. 